\title{
CONCENTRAÇÃO DE VAPOR D’ÁGUA NA ATMOSFERA DE ÁREAS URBANAS, SÃO PAULO/BRASIL
}

\author{
concentration of water vapor in the atmosphere of urban areas, São Paulo;Brazil
}

\author{
Denis Dorighello Tomás* \\ Magda Adelaide Lombardo**
}

\begin{abstract}
Resumo
O presente trabalho aborda a concentração de vapor d'água na atmosfera em áreas urbanas e as implicações destas para com este elemento constituinte da atmosfera, tendo como área de estudo a área urbanizada do município de São Paulo. O vapor d'água é o principal elemento natural existente na atmosfera gerador do chamado efeito estufa, em razão de sua capacidade em armazenar calor. A maior parte dos estudos sobre aquecimento global relacionados aos chamados gases do efeito estufa estão centrados na emissão de gases poluentes em áreas urbanizadas. Foram utilizados dados referentes a registros de umidade específica, em razão ser o modo mais eficaz de se registrar o real montante de umidade existente na atmosfera. Identificou-se tendência de aumento de concentração de vapor d'água na atmosfera da área urbana, sendo a sua evolução influenciada pela manifestação da brisa marítima, evaporação d'água das represas e pela urbanização. Contudo, não deixa de estar subordinada às condições mesoclimáticas que vigoram na região.
\end{abstract}

Palavras-chave: Climatologia, Clima urbano, Vapor d'água, Umidade específica, Áreas urbanas.

\begin{abstract}
The following research aimed to study the concentration of water vapor in the atmosphere of urban areas and its relationship with this component element of the atmosphere and it had as studied field urban of São Paulo. Water vapor is the major natural element in the atmosphere which generates the greenhouse effect because of its capacity to retain heat. The majority of studies of global warming are related to gases resulted from the greenhouse effect which are centred on the emission of pollution in urban areas. The study is made of data from records of specific humidity which is considered to be the most efficient way to record the true amount of humidity existing in the atmosphere. This research identified a tendency to increase water vapor in the atmosphere of urban area, being its evolution influenced by sea breeze, evaporation of water from dams and urbanization. However, it still subordinated to the mesoclimatic conditions in force on the region.
\end{abstract}

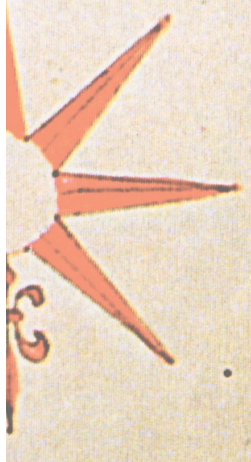

Key words: Climatology, Urban climate, Water vapor, Specific humidity, Urban areas.

\section{Resumen}

En este trabajo se hace un estudio del contenido de vapor de agua en la atmósfera en áreas urbanas y las implicaciones de estas para con este elemento constituyente de la atmósfera, teniendo como área de estudio la área urbanizada de São Paulo. El vapor de agua es lo principal elemento natural existente en la atmósfera responsable por el llamado efecto invernadero, devido su capacidad de almacenar calor. Los estudios sobre el aumento de temperatura global están centrados en los llamados gases de emisión antropogénicas termoactivos en las áreas urbanizadas. Fueran utilizados datos de registros de humedad específica, en razón de ser la manera mas correcta de registro del verdadero contenido de humedad existente en la atmósfera. La investigación identificó tendencia de aumento del contenido de vapor de agua en la atmósfera de la área urbana, siendo su evolución influyenciada por la manifestación de la brisa marítima, evaporación de agua de los embalses y por la urbanización. Todavía no deja de estar subordinado a las condiciones mesoclimáticas que vigoran en la región.

Palabras claves: Climatologia, Clima urbano, Vapor de agua, Humedad específica, Áreas urbanas.

(*) Dr. em Geografia, lotado no Ministério Público do Estado de São Paulo, Centro de Apoio Operacional Cível e de Tutela Coletiva - Rua Riachelo, nº 115, CEP: 01.007-904, São Paulo (SP), Brasil, Tel: (+55 11) 31199525 - denisdtomas@gmail.com

(**) Prof ${ }^{a}$. Dra . do Programa de Pós-Graduação em Geografia da Universidade Estadual Paulista Júlio de Mesquita Filho/Rio Claro - Av 24A, 1515, CEP: 13.506-900, São Paulo (SP), Brasil, Tel./Fax.: (+55 19) 35249622 / 35249622 - lombardo@rc.unesp.br 


\section{INTRODUÇÃO}

Abordar o assunto da umidade do ar em centros urbanos, sobretudo na área urbanizada de São Paulo, resulta de uma série de constatações tais como: os núcleos urbanos são atualmente o local onde a maior parte da população do planeta vive; os estudos de clima urbano são voltados em sua maioria para o comportamento da temperatura, das chuvas e da poluição atmosférica. Estudos de clima urbano, abordando o comportamento da umidade do ar, não são freqüentemente encontrados na literatura; a umidade do ar em áreas urbanas é matéria pouca aprofundada e controversa quanto a muitos aspectos de seu comportamento, e além de ser, a umidade existente no ar, determinante para o conforto térmico urbano e conseqüentemente dos seres vivos.

Conjuntamente, a urbanização em São Paulo mostra muitos aspectos que influenciam de maneira direta o campo térmico e higrométrico de cidades. Os vários tipos de usos e ocupações do solo, aliados aos diversos materiais utilizados nas construções, geram diferenciais de conforto térmico; surgem deste modo verdadeiras ilhas de (des)conforto térmico.

Sendo o vapor d'água um dos elementos constituintes da atmosfera, conseqüentemente do ar, apresenta como característica, "ser variável em quantidade, de acordo com a disponibilidade de água no local e energia do meio. Apesar de ser um elemento variável em tempo e espaço é extremamente importante, tanto no aspecto físico associado as sua características moleculares, como no aspecto fisiológico, decorrente de sua dependência pelos seres vivos" (OMETTO, 1981, p.157).

Tubelis (1983, p.94), abordando a existência de vapor d'água na atmosfera dispõe que "a concentração de vapor d'água na atmosfera é pequena, chegando no máximo a 4\% em volume, mas é extremamente variável. Essa variabilidade provém da extrema facilidade com que consegue mudar de fase, nas condições atmosféricas reinantes. Essas mudanças de fase são acompanhadas por liberação ou absorção de calor latente, que associadas com o transporte de vapor d'água pela circulação atmosférica, atuam na distribuição do calor sobre o globo terrestre".

Interações físicas do vapor d'água na atmosfera são responsáveis por balanço energético e conseqüentemente térmico. "A maneira como se agrupam os átomos na molécula do vapor d'água, possibilita compor uma estrutura capaz de interagir fortemente com radiações eletromagnéticas emitidas por corpos que se encontram a temperatura do meio ambiente. Essa propriedade faz com que o vapor d'água seja um armazenador de energia e, sua condição de encontrar-se dissociado no ar atmosférico possibilita sua movimentação juntamente com a deslocação do ar. A conseqüência disto é ser o vapor d'água um equalizador de energia do meio, amenizando, devido a isso as trocas de energia" (OMETTO, 1981, p.158).

Para uma dada pressão e temperatura, o ar consegue reter o vapor d'água até uma certa concentração limite. $\mathrm{O}$ ar é dito saturado quando o vapor d'água ocorre na sua concentração máxima na atmosfera. "Para o mesmo valor de pressão, essa concentração máxima ou de saturação cresce com o aumento de temperatura. Portanto, quanto maior a temperatura, maior é a capacidade do ar em reter vapor d'água" (TUBELIS, 1983, p.94).

Sendo a umidade relativa do ar inversamente proporcional à temperatura do ar, a quantificação do vapor d'água existente na atmosfera por essa maneira, permite um indicativo dessa quantidade quando não há variação da temperatura. Ocorrendo variação dessa, mesmo não havendo alteração da quantidade (acréscimo ou decréscimo) de vapor d'água existente na atmosfera, o valor indicado pelo registro de umidade relativa sofre alteração.

Assim, na realidade, apesar da umidade relativa ser a maneira mais comum de se descrever a quantidade de vapor d'água existente na atmosfera, é a mais mal entendida pela maioria das pessoas. A umidade relativa é mais indicativa do potencial da atmosfera de um determinado local, logo acima da superfície, possui em produzir chuva; quanto mais próxima dos $100 \%$ a umidade relativa estiver, mais saturada estará a atmosfera. 
O vapor d'água existente na atmosfera pode ser mensurado de uma maneira que não é influenciado pelas mudanças do volume da parcela de ar e nem pelas alterações de temperatura da mesma em curto prazo. Essa maneira de quantificar o vapor d'água da atmosfera é conhecida como umidade específica.

A umidade específica é obtida com comparação da massa de vapor d'água em uma parcela de ar com a massa total da parcela de ar (incluindo o vapor), ou seja:

\section{Umidade Específica = Massa do Vapor D’água Massa Total do Ar}

A umidade específica de uma parcela de ar permanece constante enquanto a quantidade de vapor d'água da parcela de ar não sofrer alterações (AHRENS, 1987). Isso acontece devido ao fato de que o número total de moléculas de água permanece constante mesmo se a parcela de ar se expandir ou se contrair. É importante ressaltar que a quantidade de moléculas de água que uma parcela de ar pode conter está diretamente relacionada com a energia cinética das mesmas, o que significa dizer que está relacionada com a temperatura da parcela de ar.

O tema do vapor d'água na atmosfera de centros urbanos é questão controversa. Como é exposto por Landsberg (1981), ao mesmo tempo em que os núcleos urbanos propiciam a diminuição da umidade da atmosfera, existem vários elementos/processos no urbano que servem como fornecedores de umidade para a atmosfera, bem como favorecedores de retenção de vapor d'água na atmosfera.

\section{RELEVÂNCIA DO TEMA}

A questão ambiental é um dos principais assuntos em pauta hoje nos fóruns mundiais. Esse assunto está, também, na ordem do dia de pessoas que não sabem exatamente o que isto significa e se perguntam como isso pode atingir as suas vidas e como podem contribuir para a redução dos impactos ao meio ambiente.

Desde a década de 70 a realidade da degradação ambiental tem se tornado mais aparente. As evidências mostram que os problemas ambientais se devem à combinação de vários fatores, os quais têm origem fundamentalmente no aumento dos impactos oriundos das atividades humanas por causa do aumento da população humana mundial, da produção e do uso da energia, das atividades industriais, das atividades agroindustriais, entre outras.

No rol dos problemas ambientais em pauta, destaca-se o aquecimento global. A questão do aquecimento global será uma das maiores preocupações do século XXI, tanto para os países desenvolvidos quanto para os países em desenvolvimento, segundo o estudo "GEO-2000 Global Environmental Outlook", desenvolvido pelo Programa das Nações Unidas para o Meio Ambiente - PNUMA (United Nations Environment Programme - UNEP / UNEP, 2000).

$\mathrm{O}$ aquecimento global é um impacto ambiental de amplitude global, mas que tem sua gênese na soma e acumulação de vários impactos de amplitude local. As cidades de todo o mundo geram impactos nos elementos do meio físico das áreas nas quais estão situadas, entre os quais o ar. As várias atividades exercidas no âmbito do urbano geram um aquecimento local que somado ao aquecimento de outras cidades leva ao aquecimento global.

Esse aquecimento gerado em núcleos urbanos é entendido como poluição térmica, ou seja, é a adição de calor nos ecossistemas. Exemplo de poluição térmica: nas grandes cidades são as "ilhas de calor" que retêm calor, aumentando a temperatura nesses locais, em conseqüência da retirada da cobertura vegetal, uso de materiais que absorvem grande quantidade de calor e a queima de combustíveis fósseis, entendida por muitos, a principal causa do aquecimento, devido à emissão de dióxido de carbono (CO2), o qual é o principal gás de efeito estufa.

Contudo, essa poluição térmica contribui significativamente para que haja uma maior capacidade da atmosfera que recobre as cidades em reter vapor d'água, o qual é principal agente natural 
do efeito estufa. Assim, maior o aquecimento das cidades maior capacidade em reter vapor d'água na atmosfera, conseqüentemente maior efeito estufa. Desse modo, o aquecimento global não deve ser visto apenas como uma conseqüência de emissão de gases que contribuem para o efeito estufa e sim também como conseqüência das ações do homem junto ao meio ambiente; das derivações antrópicas junto ao espaço.

O universo deste estudo é a área urbanizada do município de São Paulo, a qual se constitui como uma das áreas mais densamente ocupadas em relação aos grandes conglomerados urbanos mundiais.

Esta área urbanizada, particularmente após os anos 50, apresentou um crescimento vertiginoso, porém desordenado, devido à pressão demográfica e especulação imobiliária, as quais trouxeram, como conseqüência, um elevado grau de degradação do meio físico, biótico e social (meio ambiente). Tal área é considerada como um ótimo exemplo da transformação do meio/espaço efetivamente ocupado pelo Homem e que tem trazido alterações importantes para o meio ambiente e conseqüentemente o clima.

"No caso das metrópoles brasileiras, o intenso processo de crescimento, principalmente nas últimas décadas, desencadeou sérios problemas de degradação ambiental que afetam não apenas o espaço ocupado pela mancha urbana, mas também extrapola o nível regional" (LOMBARDO, 1995, p. 12). O mesmo pode ser inferido em relação ao clima; o crescimento urbano afeta o clima não apenas do espaço ocupado pelas áreas urbanas como também em nível regional.

Embora substanciais pesquisas tenham sido realizadas para conhecer o campo térmico urbano, sobretudo o fenômeno ilha de calor, pouco é conhecido e pesquisado sobre o campo higrométrico urbano, notadamente no que trata sobre a relação deste com os tipos de uso e ocupação do solo urbano.

Os núcleos urbanos apresentam um novo meio, onde há uma convergência de aglomeração de edificações, pessoas, fontes de produção de calor, vapor d'água e gases poluentes (calefação, indústria, automóveis, etc.). É entendido que as temperaturas elevam-se, mesmo quando diminui a duração da insolação, a umidade é reduzida e há certo aumento da precipitação.

\section{CONSIDERAÇÕES TEÓRICAS}

A concentração urbana gerada por São Paulo provocou modificações na cobertura e na estrutura da superfície do espaço ocupado pela mesma. Essa superfície, que outrora já foi conhecida como Campos de Piratininga, onde originalmente se apresentava permeável, hoje se mostra quase que completamente impermeabilizada. Os elementos constituintes desse meio foram alterados e/ ou substituídos por outros.

Com a alteração do meio, no qual está inserida a concentração humana (núcleo urbano), estabelece-se uma relação entre o núcleo e o ambiente, a qual atua sobre o sistema climático (entendido como um sistema aberto da maneira proposta por Monteiro, 1976), tanto espacial como temporalmente.

O processo de implantação humana em um determinado meio deve ser apreendido como um processo "derivador das condições primitivas do ambiente" (MONTEIRO, 1990, p.81), e que na maior parte dos casos pode atingir significativas proporções, não só pelas alterações que promove nos elementos constituintes desse meio, como também pela massa de edificações (área construída) que estabelece, tendo uma velocidade distinta dos processos naturais.

O clima urbano deve ser estudado não a partir de formulações hipotéticas assumidas por analogia. Cada núcleo estabelece uma relação com ambiente, mediante suas particularidades e peculiaridades, podendo ser mais harmoniosa ou mais conflituosa.

A relação núcleo urbano ambiente (espaço), também deve ser abordada tendo-se em consideração o contexto histórico social cultural no qual ocorre/ocorreu a ocupação do meio. A gênese desta, 
pode levar a derivações do meio completamente distintas dependendo do contexto no qual foi ou é empreendida. As derivações impostas ao meio pelas populações dos chamados países industrializados são diferentes entre si (vide Norte América e Europa) e diferenciada em relação aos países não industrializados e/ou em industrialização. Mesmo no interior de um país (Brasil, por exemplo), a ocupação do meio apresenta aspectos distintos dependendo do contexto no qual ela ocorreu/ocorre.

Cada sítio apresenta um meio e cada núcleo uma urbanização; assim não se pode inferir que dois núcleos apresentem as mesmas derivações ambientais e conseqüentemente, tais derivações influam da mesma maneira no sistema climático.

O elemento climático mais sensível ou que responde mais rapidamente a essas derivações é a temperatura do ar. O campo térmico urbano normalmente apresenta acréscimo em seus valores; em várias cidades do planeta esse fenômeno já foi observado/estudado, inclusive em São Paulo (LOMBARDO, 1985).

Pode-se inferir a partir dessa constatação que, conseqüentemente, a umidade do ar também é afetada. Normalmente entende-se que os centros urbanos apresentam uma menor umidade do ar. De um modo geral a umidade da qual se está referindo é a umidade relativa do ar. O que na verdade poderia ser entendido como uma constatação do distanciamento da temperatura do ponto de orvalho, ou seja, a saturação do ar passa ocorrer de modo mesmo freqüente.

As intervenções do homem sobre o meio primitivo podem variar de mero assentamento de construção de edificações para a moradia até remodelações fisiográficas/topográficas.

As derivações antrogênicas no espaço ocupado pela área urbanizada de São Paulo, entre várias, estabeleceram uma série de obras para produção de energia elétrica e regularização das vazões dos principais cursos d'água (rio Tietê e Pinheiros) da bacia sedimentar paulistana. Reservatórios de água foram criados para tanto; entre eles Guarapiranga e Bilings, formando o que se pode considerar de todo um sistema lacustre. "Associou-se a êsse quadro físico outro elemento da paisagem paulistana: a enorme superfície de águas retidas sôbre a parte meridional da região, nas represas da Cia. Light \&Power" (FRANÇA, 1946, p.19).

Essas derivações alteraram substancialmente a paisagem da bacia paulistana e foram incorporadas de tal maneira a mesma que grande parte da população as assume como sendo intrínsecas ao meio primitivo da bacia sedimentar.

A presença desses reservatórios condicionou em boa parte a ocupação na bacia paulistana e ao mesmo tempo propiciou condições climáticas locais. França (1946, p.19), destaca que a alta umidade da porção meridional da cidade de São Paulo, em decorrência de sua proximidade ao oceano, estando mais sujeita às penetrações da brisa marítima, é agravada pela "extensa superfície líquida das represas da Light".

Estudos abordando a existência de corpos d'água (lagos, represas, reservatórios, etc) e suas influências sobre o clima local, colocam que tais influências estão diretamente relacionadas com o tamanho do corpo d'água, disposição do mesmo (localização), situação topográfica da localização, tipo de uso de ocupação do solo do entorno, sistemas atmosféricos atuantes na região, entre outros fatores.

Deve-se ressaltar que existem pesquisas realizadas as quais demonstram que mesmo pequenos corpos d'água podem gerar influências no clima das áreas lindeiras dos mesmos. Saaroni \& Ziv (2003), estudando os impactos de um pequeno lago (04 ha) na cidade de Tel Aviv, Israel, reporta que o mesmo condiciona a velocidade do vento e temperatura nas áreas ao redor em situações distintas de tipos tempo.

Freitas \& Silva Dias (2004), estudando os efeitos causados pela presença das represas Billings e Guarapiranga nas condições atmosféricas da Região Metropolitana de São Paulo por meio de modelagem numérica da atmosfera utilizando o Regional Atmospheric Modeling System (RAMS), identificam circulações do tipo brisa lacustre decorrentes da existência dos reservatórios, as quais causam alterações sobre os campos de temperatura, umidade e vento. 
A brisa lacustre está diretamente relacionada ao conteúdo de umidade do solo, às características aerodinâmicas e dos materiais da superfície no entorno do corpo d'água. Simulações realizadas por Shen (1998), citado por Stivari (1999), utilizando um modelo numérico bidimensional, demonstram o impacto sobre a brisa lacustre quando há alterações dos padrões de cobertura da superfície de áreas adjacentes aos corpos d'água. Quanto menor a quantidade de umidade na superfície adjacente, maior é a intensidade da brisa lacustre.

Pesquisas realizadas no Brasil como de Guidon (1991), investigando possíveis alterações climáticas na região de Tucuruí em decorrência da formação do lago da hidrelétrica de Tucuruí, e de Stivari (1999), também investigando possíveis alterações climáticas resultantes da criação do lago da hidrelétrica de Itaipu, comprovam a manifestação de brisa lacustre em razão dos mesmos e que o padrão de movimento (direção e intensidade) de tal brisa está diretamente relacionado com o tipo de uso e ocupação do solo do entorno imediato dos lagos.

Mudanças na cobertura da superfície das áreas contíguas aos corpos d'água afetam diretamente o balanço energético entre as superfícies aquáticas e terrestres, levando a modificações do comportamento do surgimento e do deslocamento da brisa lacustre.

Da mesma maneira como atua sobre a formação, intensidade e potencial de deslocamento (campo de influência) da brisa lacustre, os fatores acima citados agem também na capacidade de penetração/deslocamento da brisa marítima sobre uma dada região.

No caso da área urbanizada de São Paulo, a brisa marítima é componente importante a ser considerado na caracterização do seu clima, tendo em visa que o centro da cidade de São Paulo está aproximadamente a $60 \mathrm{~km}$ da linha da costa. Cabral (2002), abordando o assunto, explana que as condições de umidade, temperatura e nebulosidade da área urbana paulistana são afetadas de maneira significativa pela brisa marítima.

A influência da brisa marítima sobre elementos climáticos da área urbana de São Paulo foi constatada por Oliveira \& Silva Dias (1981), em estudo de identificação da penetração da mesma sobre a cidade. Constataram, por meio de análise de série histórica de dados da estação meteorológica do IAG, que a circulação térmica associada à brisa marítima condiciona o campo do vento, da umidade e da temperatura em meso-escala na região da cidade de São Paulo. A caracterização da penetração da brisa marítima na área de São Paulo se dá pela variação brusca dos elementos acima identificados, a qual ocorre no período da tarde, influindo de modo decisivo nas condições climáticas da região.

Pereira Filho et al. (2002), em estudo sobre o caso da enchente repentina do túnel do Anhangabaú em primeiro de março de 1999, verificaram que a tempestade foi um resultado da interação entre a ilha de calor urbana e a penetração da brisa. Constatam que cerca de $60 \%$ dos casos de enchente ocorridos na Região Metropolitana de São Paulo - RMSP, entre março de 1999 e março de 2002 estavam associados à penetração de brisa marítima no período da tarde.

Estudo realizado por Sias \& Silva Dias (2002), sobre caso de precipitação extrema na cidade de São Paulo, colocam que a brisa marítima exerce um papel importante no regime de chuvas, principalmente, na faixa leste do Estado, porém, essa característica se evidencia mais no verão.

A maior parte da área urbanizada metropolitana de São Paulo está situada em bacia sedimentar em situação altimétrica inferior às formações de serrania que a limita, e em sua porção Sul apresenta uma conformação morfológica favorável à penetração da brisa marítima, o que se alia aos ventos predominantes da região que são de Sul e Sudeste.

França (1946, p. 39) salienta esse fato dispondo que a cidade situando-se "a distância relativamente pequena do litoral, é certo que as brizas do mar, que sopram normalmente naquela área, chegam à capital paulista (...). Ao Sul da cidade, a bacia de S. Paulo apresenta, uma passagem ampla, que é percorrida, na entrada da noite, pela brisa marítima. Soprando depois do máximo diurno das 14 horas, essas brisas frescas são verdadeiras "duchas" que o paulistano recebe antes do anoitecer 
e um dos fatores mais favoráveis à atividade humana. As observações, a partir das 15 horas, ( e as das 21 horas, nos pontos que fizeram registro tri-diurno do vento - o antigo da Av. Paulista, o do Butantã), registraram durante todo o ano o sopro regular da briza de SE, ativado no verão e na primavera, em conseqüência da depressão de origem térmica, que se forma sobre a região de $S$. Paulo, sendo também observada nas outras estações".

É importante ressaltar que a umidade do ar referenciada pelos estudos acima mencionados, assim como outros que também abordam a temática da brisa marítima, brisa lacustre e umidade do ar, em sua maioria, é a umidade relativa do ar.

Como anteriormente exposto, a umidade relativa não é a melhor maneira de se quantificar a real quantidade de vapor d'água existente na atmosfera sobre um determinado local, uma vez que está diretamente relacionada com a temperatura do ar. Desse modo, não possibilita um perfeito entendimento da variação do vapor d'água na atmosfera.

Pode-se inferir pela teoria que, ocorrendo aumento da temperatura do ar a umidade especifica também aumentaria, pois com aumento da temperatura do ar há uma maior capacidade do ar em reter água em forma de vapor. Isso decorre do fato de que quantidade de moléculas de água que uma parcela de ar pode conter está diretamente relacionada com a energia cinética das mesmas, o que significa dizer que está relacionada com a temperatura da parcela de ar.

Ocorrendo a formação de fenômeno ilha de calor em núcleos urbanos, há conseqüentemente aumento da capacidade da atmosfera acima desses núcleos em reter vapor d'água. Pode-se inferir que a umidade específica aumenta.

O vapor d'água existente na atmosfera é um dos principais componentes de formação natural do efeito estufa. Havendo uma maior concentração de vapor d'água na atmosfera dos núcleos urbanos, resulta em um maior aquecimento dos mesmos em decorrência da intensificação do efeito estufa, gerado por uma maior quantidade de moléculas d'água existentes na atmosfera.

\section{MATERIAL E MÉTODOS}

A pesquisa pautou-se pelo tratamento estatístico dos dados de umidade específica, os quais foram analisados conjuntamente com dados de temperatura do ar, temperatura do ponto de orvalho, umidade relativa, pressão atmosférica, precipitação e ventos. Foram utilizados dados da estação meteorológica do Instituto Astronômico e Geofísico da Universidade de São Paulo - IAG/USP (Estação Meteorológica da Água Funda).

A série histórica de dados coletados corresponde a um lapso temporal de 41 anos, compreendendo o período dos anos de 1960 a 2000 inclusive.

Para cada ano das séries de dados, foi calculada a média aritmética com a finalidade de obter-se a média diária, mensal e anual da umidade específica, temperatura do ar, temperatura do ponto de orvalho, umidade relativa, pressão atmosférica no caso dos dados da estação do IAG; no caso da estação do Mirante de Santana foi calculada a média aritmética com a finalidade de obter-se a média anual da temperatura do ar e umidade relativa.

Quanto aos dados de ventos referentes à estação do IAG, estes foram agrupados em razão de sua predominância (freqüência) diária, posteriormente mensal e finalmente anual, com suas respectivas intensidades (velocidades).

A análise os dados de umidade específica foi realizada de modo a verificar influências e correlações com a manifestação da brisa marítima, a evaporação d'água decorrente das represas Billings e Guarapiranga e a urbanização da área de entorno da estação meteorológica do IAG.

Para apreender os possíveis impactos da urbanização na concentração de vapor d'água sobre áreas urbanas, necessário ter conhecimento dos tipos de uso e ocupação do solo da área urbanizada objeto de estudo. Esta premissa advém do conhecimento de estudos já realizados como Lombardo (1985), Brandão (1996), Tarifa \& Azevedo (2001), entre outros, nos quais fica evidenciado que a 
influência do meio/espaço urbanizado sobre a temperatura decorre do tamanho da área construída, concentração de áreas construídas, geometria e tipos dos prédios, número de habitantes, densidade da população, entre outros fatores.

Deste modo, adotou-se uma área amostral, a qual corresponde ao local onde está situada a estação meteorológica do IAG e seu entorno imediato, compreendendo uma área quadrada de $25 \mathrm{Km} 2$, tendo como centro a estação meteorológica, para averiguar os possíveis impactos da urbanização na concentração de vapor d'água na atmosfera. A adoção de tal área amostral também foi determinada pelo fato de somente se utilizar dados de umidade específica da estação meteorológica do IAG.

Para a identificação dos tipos de uso do solo e dos materiais de cobertura da superfície, foi realizada fotointerpretação da área de entorno imediato do local de registro, correspondendo a uma área de $25 \mathrm{Km} 2$, nos moldes descritos por Tomás (1999). utilizando-se imagem de satélite Ikonos, escala original 1:2.000, reduzida para 1:25.000, para o ano de 2000, e fotografia área deste mesma área referente a levantamento aerofotogramétrico de 1962 na escala de 1:25.000.

Também, foi coletada série histórica de dados, referente ao volume da água e superfície ocupada pelo mesmo, dos reservatórios Billings e Guarapiranga, junto a Empresa Metropolitana de Águas e Energia S. A. - EMAE. Dados sobre o montante de evaporação d'água referentes aos reservatórios também foram coletados. Os dados obtidos são referentes a Evaporímetros de tanque terrestre tipo Classe A, de responsabilidade da EMAE. Os dados correspondem a registros mensais dos postos Barragem das Pedras (P12-002), Pedreira (P12-042) e Guarapiranga (P12-099), compreendendo os anos 1960 a 2000, inclusive.

\section{RESULTADOS E DISCUSSSÃO}

Estudar a concentração de vapor d'água existente na atmosfera de áreas urbanizadas não se restringe somente ao conhecimento de climatologia urbana. Possibilita adentrar no campo do conhecimento humano sobre o meio ambiente, das relações entre o homem e o meio, o que se iguala a dizer da construção espaço geográfico, sendo assim um estudo essencialmente geográfico.

$O$ vapor d'água é um elemento natural constituinte da atmosfera, o qual é essencial no balanço térmico do sistema climático, sendo o principal elemento para a manifestação do efeito estufa. As preocupações ambientais atuais sobre o aquecimento global quase não levam em consideração a importância desse elemento no contexto dos gases responsáveis pelo efeito estufa, o qual leva ao aumento da temperatura do planeta.

Os estudos de climatologia urbana que abordam a concentração de vapor d'água em áreas urbanizadas são poucos, sobretudo os que tratam com registros de umidade do ar de estações meteorológicas fixas, tanto em países desenvolvidos, correspondendo a dizer em países de clima temperado, como nos paises em desenvolvimento, quase todos em áreas de clima tropical.

Entende-se que clima urbano como um sistema aberto, o qual resulta da interação entre atmosfera e área urbanizada, ou seja, entre os tipos de estados atmosféricos reinantes sobre a área urbanizada e as atividades, usos e ocupações que se manifestam no espaço/superfície ocupada pela área urbanizada, sendo que ambos, em uma visão sistêmica, atmosfera e área urbanizada, são agentes modelados e modeladores, sujeitos a influências externas.

A área urbanizada objeto do presente estudo é marcada essencialmente pela ausência de planejamento a longo prazo e pela geração de impactos significativos ao meio ambiente, afetando todos os seus elementos constituintes, dentre eles o clima.

Atualmente o clima da área urbanizada de São Paulo é conhecido pelos aspectos desfavoráveis, com destaque para a poluição atmosférica, chuvas torrenciais, aumento da temperatura e situações de desconforto térmico. Todas essas manifestações, via de regra, estão associadas à áreas urbanas cujos tipos de usos e ocupação do solo se caracterizam por alto adensamento, solo impermeabilizado e escassez de áreas verdes. 
Os resultados encontrados na pesquisa mostram existir aumento da concentração de vapor na área urbanizada de São Paulo. Esse aumento se manifesta em termos anuais e sazonais, exceção à estação de Inverno. Identificou-se, para o período estudado, que a tendência de aumento do vapor d'água se manifesta após a década de 70 do século XX.

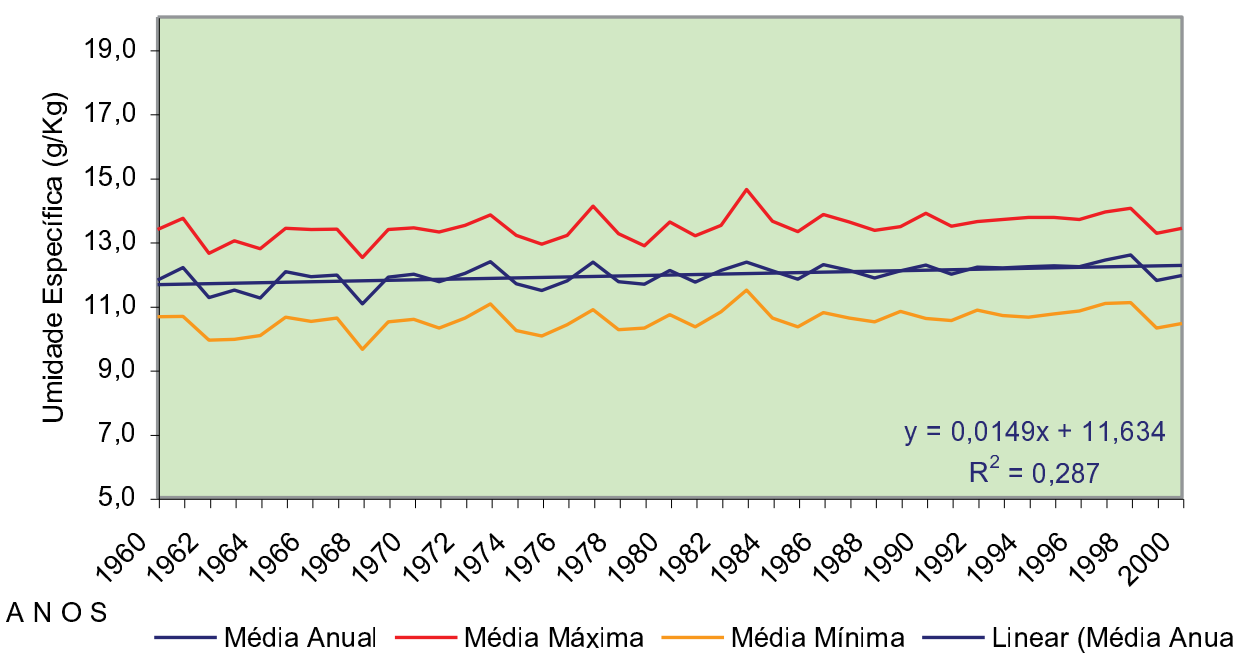

Figura 1 - Média Anual Umidade Específica Estação IAG 1960-2000

Na figura 1 é apresentada a média anual dos valores registrados de umidade específica e a reta de regressão linear, no qual se pode observar que para o período é identificada uma tendência para aumento dos valores da umidade específica.

Em termos mensais (figura 2) as maiores quantidades de vapor d'água na atmosfera ocorrem nos meses de outubro a março (estação de primavera e verão), enquanto as menores concentrações ocorrem nos meses de abril a setembro (estação de outono e inverno).

A concentração de vapor d'água na atmosfera apresenta um ritmo diário no qual a maiores quantidades de vapor ocorrem no período vespertino, sobretudo após as 14:00 horas, tendo os seus máximos se manifestando entre 17:00 e 18:00 horas.

Constatou-se que a quantidade de vapor d'água na atmosfera da área urbanizada acompanha diretamente o ritmo da temperatura do ar em termos diário, mensal e anual (figura 3).

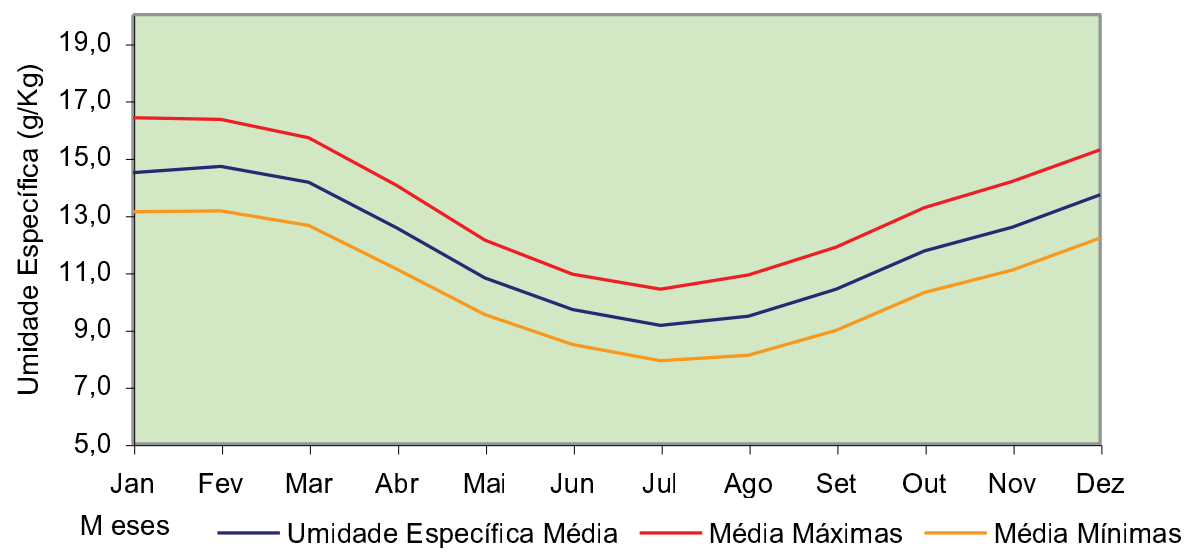

Figura 2 - Média Mensal Umidade Específica Estação IAG Período 1960-2000 


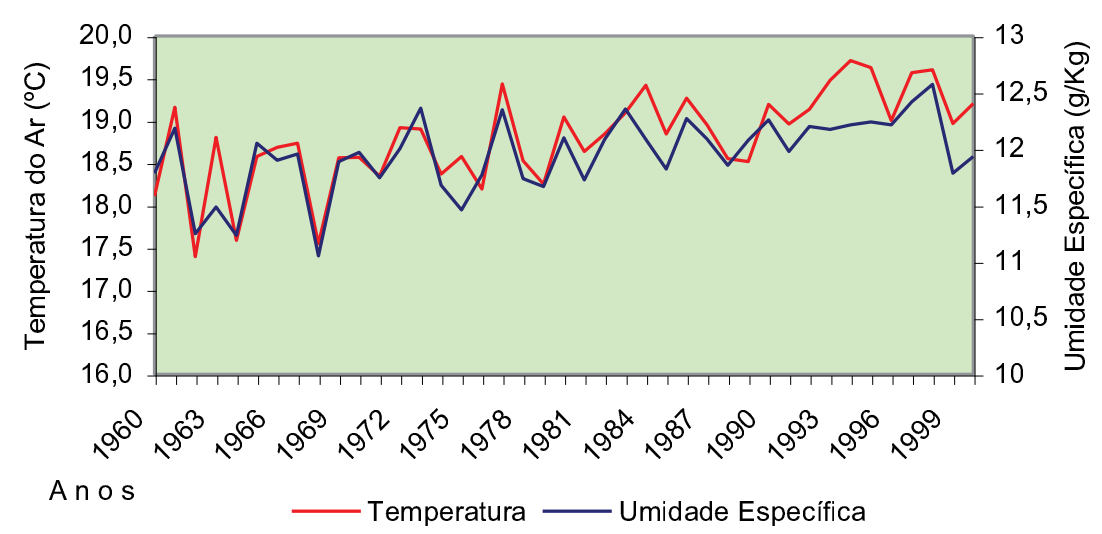

Figura 3 - Média Anual Temperatura do Ar e Umidade Específica Estação IAG Período 1960-2000

Para as 04 décadas abarcadas pelo estudo (tabela 1), foi observado o aumento da quantidade de vapor d'água tanto em nível anual, sazonal e horário. Os maiores valores de concentração de vapor d'água foram registrados no decorrer da década de 90 do século XX. O mesmo padrão foi identificado para a temperatura do ar.

Tabela 1 - Média Decenais Anuais Umidade Específica (g/Kg)

\begin{tabular}{c|c|c|c|c|c}
\hline & ANUAL & VER & OUT & INV & PRI \\
\hline $60 / 69$ & 11,7 & 14,0 & 10,6 & 9,5 & 12,5 \\
\hline $70 / 79$ & 11,9 & 14,3 & 10,9 & 9,8 & 12,5 \\
\hline $80 / 89$ & 12,0 & 14,6 & 11,4 & 9,6 & 12,7 \\
\hline $90 / 99$ & 12,2 & 14,8 & 11,2 & 9,8 & 12,9 \\
\hline
\end{tabular}

Identificou-se que os fluxos de ventos que se manifestam na região da área urbanizada de São Paulo, atuam diretamente sobre o montante de vapor d'água existente na atmosfera. As maiores quantidades de umidade no transcorrer do dia são registradas no período da tarde (figura 4); período no qual há predomínio de ventos da direção Sudeste e ocorre a penetração da Brisa Marítima, a qual possui alto teor de umidade.

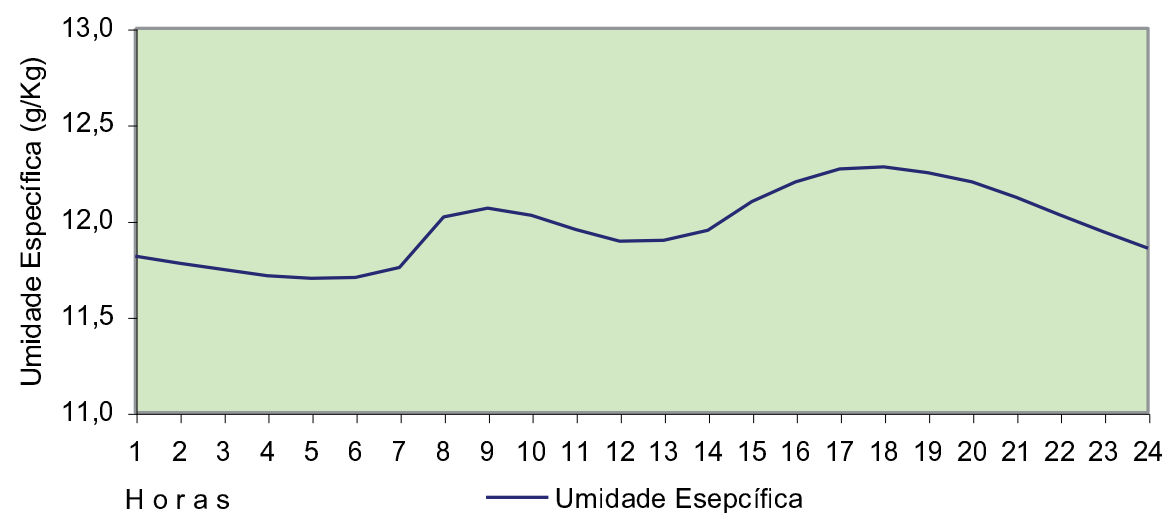

Figura 4 - Média Horária Umidade Esepcífica Estação IAG Período 1960-2000.

A existência de corpos d'água de tamanho considerável na porção Sudeste, Sul e Sudoeste da 
área urbanizada do município de São Paulo (represas Billings e Guarapiranga), contribui para o montante de vapor d'água existente na atmosfera da área urbanizada.

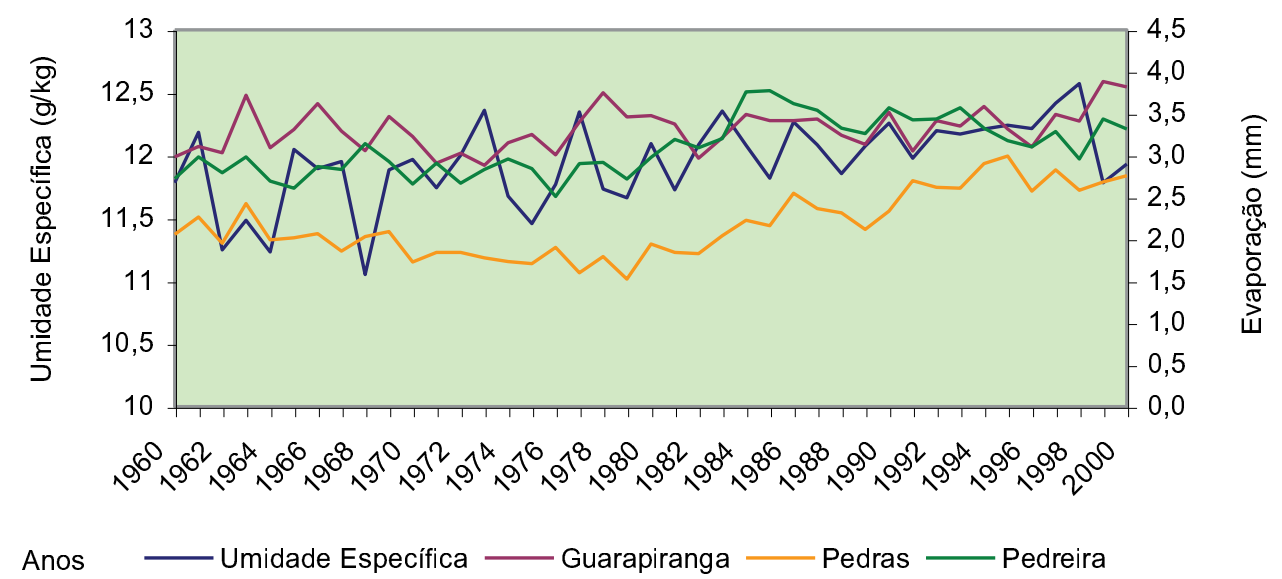

Figura 5 - Média Anual Umidade Específica IAG e Evaporação Postos Pedreira, Guarapiranga e Pedras Período 1960-2000

$\mathrm{Na}$ figura 5 pode-se observar que, apesar das curvas dos registros médios de umidade específica e de evaporação dos postos de evaporímetros considerados não apresentarem, de um modo geral, uma similitude quanto ao comportamento, possuem em comum a característica de mostrarem tendência de aumento dos valores registrados em momento coincidente, o qual se manifesta depois de meados da década de 70 do século XX.

Período que reflete a influência do processo de urbanização sofrido nas áreas de entorno das estações meteorológicas de Pedreira e do Guarapiranga, e no caso da estação de Pedras o desmatamento como um todo da bacia hidrográfica do Alto Tietê.

O acompanhamento da evolução da urbanização na área onde está localizada a estação meteorológica do IAG permitiu identificar os possíveis impactos da urbanização no comportamento do vapor d'água na atmosfera da área urbanizada metropolitana de São Paulo. Toda a área do entorno da estação, exceção da área do Parque Estadual, foi ocupada, passando de área onde predominavam superfícies permeáveis no ano de 1962 para uma área na qual há predomínio das superfícies impermeabilizadas no ano de 2000 (figura 6). Isto acarretou alteração do balanço térmico e higrométrico, em razão dos materiais utilizados neste processo de ocupação, em sua maioria, serem favoráveis a que haja uma maior temperatura e evaporação rápida de água, contribuindo para uma maior concentração de vapor d'água na atmosfera.

A figura 7 mostra a correlação linear entre a área construída no entorno da estação e as médias de umidade específica para anos de 1962, 1972, 1994 e 2000. Em termos estatísticos não há uma boa correlação em razão do coeficiente de determinação não ser significativo ( $\mathrm{r} 2=0,6559)$.

Os dados da área construída são referentes aos anos de 1962, 1972 e 1994, e são os utilizados por Tomás (1999); o dado da área construída do ano de 2000 é referente a fotointerpetração realizada utilizando-se a imagem de satélite Ikonos do ano 2000. 

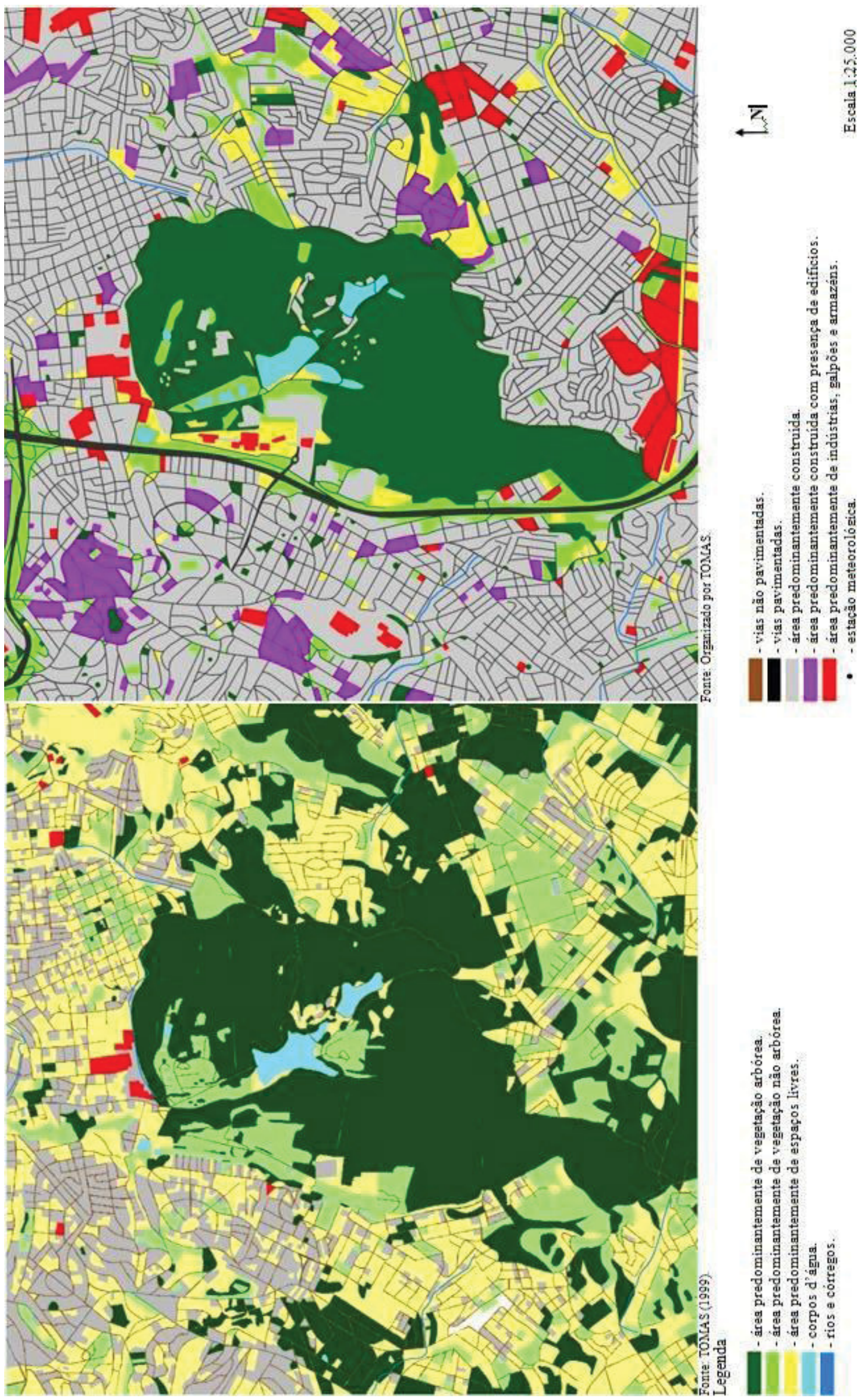

Figura 6 - Urbanização da área do entorno da estação meteorológica do IAG/USP Fonte: Tomás (2004) / obs.: desenho reduzido. 


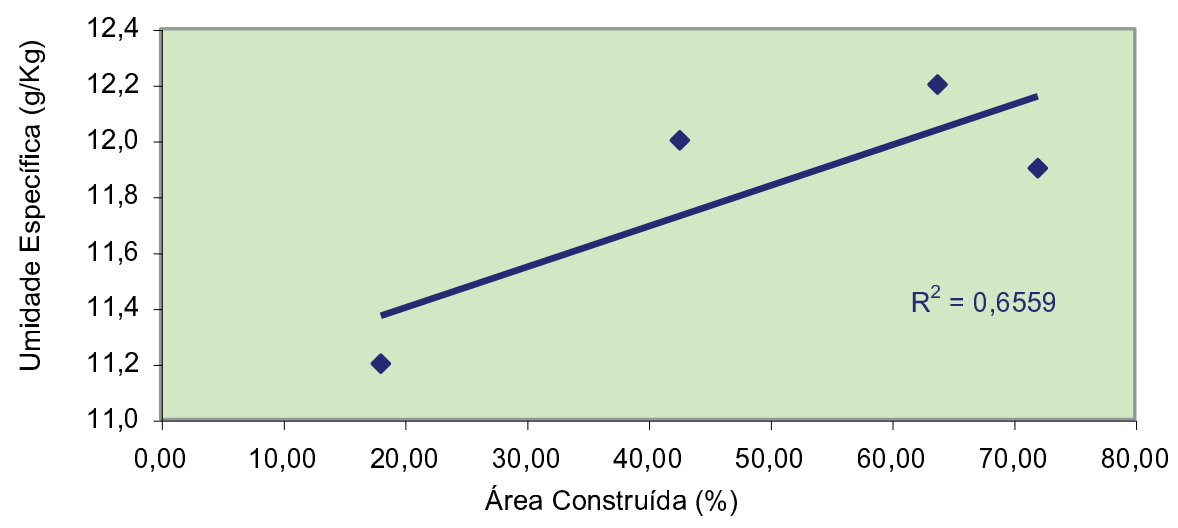

Figura 7 - Correlação entre as Médias de Umidade Específica e Área Construída no Entorno da Estação IAG - Anos 1962, 1972, 1994 e 2000.

$\mathrm{Na}$ Geografia de um modo geral e no presente caso em particular, os fenômenos estudados possuem caráter multivariado. Em outras palavras, uma dada variável pode ser influenciada por várias outras além daquela com a qual se relaciona diretamente num determinado estudo. Na presente pesquisa, é perceptível que o comportamento da umidade específica é influenciado pelo aumento da área construída. Mas esse aumento tem apenas uma parcela de responsabilidade na variação da umidade específica.

\section{CONSIDERAÇÕES FINAIS}

Evidenciou-se que a acentuada urbanização que se manifesta na área urbana de São Paulo influencia na quantidade de vapor d'água existente na atmosfera, que a brisa marítima possui relação direta com o comportamento do vapor d'água na atmosfera e que os reservatórios Billings e Guarapiranga contribuem para o montante de umidade na atmosfera da área urbanizada de São Paulo; além de evidenciar que o comportamento do vapor d'água na atmosfera não deixa de estar subordinado às condições mesoclimáticas que vigoram na região.

Mesmo que a as intervenções humanas no meio ambiente não sejam a principal causa das mudanças climáticas, devem ser cautelosas, sobretudo as que tenham o potencial de interferir no sistema climático urbano.

As derivações antropogênicas causam, em sua maior parte, aumento da temperatura do ar em núcleos urbanos, essas mesmas derivações estão contribuindo para uma maior capacidade da atmosfera em reter vapor d'água, conseqüentemente propiciando mais efeito estufa e por fim um maior aquecimento global.

Não se pode falar que somente as emissões de gases de efeito estufa decorrentes das atividades urbano-industriais sejam responsáveis pelo aquecimento global, talvez sejam a maior componente, mas há de se falar também, quando esse assunto é abordado, do efeito estufa gerado pelas áreas urbanizadas, em razão das mudanças de uso e ocupação do solo que favorecem ao acumulo de vapor d'água na atmosfera.

\section{REFERÊNCIA BIBLIOGRÁFICA}

AHRENS, C. D. Meteorology Today: Introduction to Weather, Climate and the Environment. New York: Ed. West Publishing Company, 1987.

BRANDÃO, A. M. P. M O clima urbano da cidade do Rio de Janeiro. 1996. 362 p. Tese (Doutorado em Geografia) - Departamento de Geografia, Faculdade de Filosofia, Letras e Ciências Humanas da Universidade de São Paulo, São Paulo. 
CABRAL, E. Tendências e Variabilidade do Fenômeno Pluvial na Região Metropolitana de São Paulo e Possíveis Vinculações com o Processo de Urbanização. 2002. 183 p. Tese (Doutorado em Geografia) - Departamento de Geografia, Faculdade de Filosofia, Letras e Ciências Humanas da Universidade de São Paulo, São Paulo.

FRANÇA, A. Estudo sobre o clima da bacia de São Paulo. 1946. 59p. Tese (Doutorado em Geografia). In: Boletim LXX da Faculdade de Filosofia, Ciências e Letras da Universidade de São Paulo.

FREITAS, E. D.; SILVA DIAS, P. L. Os Efeitos da Brisa Lacustre Sobre as Condições Atmosféricas da Região Metropolitana de São Paulo. In: CONGRESSO BRASILEIRO DE METEOROLOGIA, XIII, 2004, Fortaleza. Anais... (CD), Fortaleza: SBMET, 2004.

GUIDON, M. A. A. De O. Estudo das variações climáticas na área do Lago de Tucuruí. 1991. Dissertação (Mestrado em Geografia) - Departamento de Geografia, Faculdade de Filosofia, Letras e Ciências Humanas, Universidade de São Paulo, São Paulo.

LANDSBERG, H. E. Urban climates. New York: Academic Press, 1981.

LOMBARDO, M. A. Ilha de Calor nas Metrópoles: O Exemplo de São Paulo. São Paulo: Ed. Hucitec, 1985. $244 \mathrm{p}$.

LOMBARDO, M. A. Qualidade Ambiental e Planejamento Urbano. 1995. Tese (Livre Docência em Geografia) - Departamento de Geografia, Faculdade de Filosofia, Letras e Ciências Humanas da Universidade de São Paulo.

MONTEIRO, C. A. De F. Teoria e Clima Urbano. 1975. Tese (Livre Docência em Geografia) - Departamento de Geografia, Faculdade de Filosofia, Letras e Ciências Humanas da Universidade de São Paulo, São Paulo.

MONTEIRO, C. A. De F. A cidade como Processo Derivador Ambiental e a Geração de um Clima Urbano: Estratégias na Abordagem Geográfica. Revista do Departamento de Geociências - GEOSUL, Florianópolis, SC, n. 9, ano V, p. 80-114, 1990.

OLIVEIRA A. P.; SILVA DIAS, P. L. Aspectos Observacionais da Brisa Marítima em São Paulo. In: CONGRESSO BRASILEIRO DE METEOROLOGIA, II, 1981, Pelotas. Anais... Pelotas: SBMET, 1981, p. 129-161.

OMETTO, J. C. Bioclimatologia Vegetal. São Paulo: Ed. Agronômica Ceres, 1981. 440p.

PEREIRA FILHO, A. J.; HAAS, R.; AMBRIZZI, T. Caracterização de eventos de enchente na bacia do Alto Tietê por meio do radar meteorológico e da modelagem numérica de mesoescala. In: CONGRESSO BRASILEIRO DE METEOROLOGIA, XII, 2002, Foz do Iguaçú. Anais... (CD), Foz do Iguaçú: SBMET, 2002, p. 391-398.

SAARONI, H.; ZIV, B. The impact of a small lake on heat stress in a Mediterranean urban park: the case of Tel Aviv, Israel. International Journal of Biometeorology, v. 47, p. 156-165, 2003.

SIAS, E. E.K.; SILVA DIAS, M. A. F. Análise de um Caso de Precipitação Extrema no Inverno na Cidade de São Paulo. In: CONGRESSO BRASILEIRO DE METEOROLOGIA, XII, 2002, Foz do Iguaçú. Anais... (CD), Foz do Iguaçú: SBMET, 2002, p. 4011-4020.

STIVARI, S. M. S. Um Estudo da Brisa Lacustre do Lago de Itaipu. 1999. 126 p. Tese (Doutorado em Meteorologia) - Departamento de Ciências Atmosféricas, Instituto de Astronomia, Geofísica e Ciências Atmosféricas da Universidade de São Paulo, São Paulo.

TARIFA, J. R.; AZEVEDO, T. R. De Os Climas na Cidade de São Paulo: Teoria e Prática. São Paulo: Pró-Reitoria de Cultura e Extensão. Universidade de São Paulo: Laboratório de Climatologia. Faculdade de Filosofia. Letras e Ciências Humanas, Universidade São Paulo, 2001. 199p. (GEOUSP - Coleção Novos Caminhos, 4).

TOMÁS, D. D. Comportamento da Umidade Relativa do Ar em Centros Urbanos: O Exemplo da Metrópole de São Paulo. 1999. 278 p. Dissertação (Mestrado em Geografia) - Departamento de Geografia, Faculdade de Filosofia, Letras e Ciências Humanas da Universidade de São Paulo, São Paulo.

TOMÁS, D. D. Concentração de Vapor D’água na Atmosfera de Áreas Urbanas: o exemplo de São Paulo. 2004. 122 p. Tese (Doutorado em Geografia) - Departamento de Geografia, Faculdade de Filosofia, Letras e Ciências Humanas da Universidade de São Paulo, São Paulo. 
TUBELIS, A. \& NASCIMENTO, F. J. DE Meteorologia Descritiva: fundamentos e aplicações brasileiras. São Paulo: Ed. Nobel, 1980. 374p.

UNEP GEO-2000 Global Environmental Outlook. Nairobi, Kenya: United Nations Environment Program. Cheatle, M.; Schomaker, M.; Seki, M.; Vandeweerd, V. and Zahedi, K. (coordinating team), 2000.

Trabalho enviado em abril de 2012 Trabalho aceito em junho de 2012 